\title{
Absence of the Platelet Receptor for Drug-Dependent Antibodies in the Bernard-Soulier Syndrome
}

\author{
Thomas J. Kunicki, Margaret M. Johnson, and Richard H. Aster, Milwaukee \\ Blood Center, Inc.; the Department of Biology, Marquette University; the \\ Department of Medicine, Medical College of Wisconsin, Milwaukee, Wisconsin \\ 53233; and the Wilmington Medical Center, Wilmington, Delaware 19899
}

\begin{abstract}
A B S TRACT The platelet membrane receptor for quinidine- and quinine-dependent antibodies was studied in three patients with the Bernard-Soulier syndrome (BSS) and in normal subjects with immunologic techniques based on the release of ${ }^{51} \mathrm{Cr}$ from labeled platelets. The receptor could not be detected on BSS platelets but was present on platelets from each of 180 normal subjects. BSS platelets reacted normally with other allo- and autoantibodies. In confirmation of previous reports, BSS platelets were found to be deficient in glycoproteins Ib and Is. However, after apparently total cleavage of these proteins from the membrane of normal platelets by controlled hydrolysis with trypsin or chymotrypsin, $80 \%$ of the drug-dependent antibody receptor activity was retained. These observations suggest the existence of an additional, hitherto unrecognized membrane defect in BernardSoulier platelets.
\end{abstract}

\section{INTRODUCTION}

The Bernard-Soulier syndrome (BSS) ${ }^{1}$ is an inherited disorder of blood platelets characterized by reduced platelet-subendothelial adherence $(1,2)$, moderate thrombocytopenia, a long bleeding time, and giant platelets in the peripheral blood smear (1-3). BSS platelets, in contrast to normal platelets, fail to aggregate in response to bovine Factor VIII $(2,4)$ or human Factor VIII and ristocetin, but respond normally to other aggregating agents such as adenosine diphosphate $(2,5,6)$. Deletion of a platelet membrane glycoprotein, designated glycoprotein I (GPI), ${ }^{2}$ in BSS was

\footnotetext{
Received for publication 30 May 1978.

${ }_{1}$ Abbreviations used in this paper: BSS, Bernard-Soulier syndrome; GPI, glycoprotein I.

2 The membrane glycoprotein terminology originally proposed by Phillips (7) is used with the modification for the GPI complex proposed by Nurden and Caen (8), that is, GPIb$\alpha$, membrane bound; GPIs, soluble, identical to glycocalicin (9); GPIg, granule associated, mol wt 145,000-155,000;
}

first reported by Nurden and Caen (10). With newer analytic methods capable of resolving the GPI band into three proteins on sodium dodecyl sulfate polyacrylamide gel electrophoresis, this abnormality has been more precisely defined as a deficiency of both GPIb and GPIs but not of GPIg $(8,11)$.

Our recent observation of a deletion of the alloantigen $\mathrm{Pl}^{\mathrm{A} 1}$ from platelets of patients with Glanzmann's thrombasthenia (12) prompted us to evaluate platelet-specific antigen markers in BSS platelets. We here report the apparently unique deletion from BSS platelets of a membrane receptor (antigen?) specific for quinidineand quinine-dependent platelet antibodies.

\section{METHODS}

Patient selection. Each of the three patients studied fulfilled the diagnostic criteria of BSS noted above. Patients 1 and 2 were first cousins who have been the subjects of several previous studies $(2,13,14)$. Patient 3 was kindly referred by Dr. Scott Murphy of Philadelphia, Pa.

Methods. Platelets were isolated by differential centrifugation as previously described (12) except that residual erythrocytes were washed three additional times with EDTA in $145 \mathrm{mM} \mathrm{NaCl}$ to increase platelet yields. Clumping of platelets, characteristic of BSS, was observed in each preparation. This was reversed by repeated centrifugation and resuspension of the isolated platelets. The final yield of platelets from each preparation of whole blood was $\cong 70 \%$. Final preparations contained fewer than one erythrocyte or leukocyte per 1,000 platelets.

Selection of antibodies reactive with $\mathrm{Pl}^{\mathrm{A} 1}$ antigen, quinidine- and quinine-dependent antiplatelet antibodies, and autoantibodies of idiopathic thrombocytopenic purpura and techniques for ${ }^{51} \mathrm{Cr}$-labeling of platelets, the ${ }^{51} \mathrm{Cr}$-release assay, and assay of antibody-reactive sites by inhibition of ${ }^{51} \mathrm{Cr}$ release have been described (12).

Membrane glycoproteins were separated by polyacrylamide gel electrophoresis of solubilized whole platelets with or without $10 \%$ 2-mercaptoethanol, followed by scanning

GPIIb $\alpha$, mol wt 132,000; GPIIIa, mol wt 115,000. Molecular weight values are those determined in fully reduced (10\% 2-mercaptoethanol) samples. 
densitometry of periodic acid Schiff reagent-stained gels $(7,12)$.

\section{RESULTS}

Antibody-induced release of ${ }^{51} \mathrm{Cr}$ from platelets. In contrast to platelets from each of 180 normal subjects studied in our laboratory, platelets from the three BSS patients failed to respond to quinine- and quinidinedependent antibodies by releasing ${ }^{51} \mathrm{Cr}$ (Fig. 1). Platelets from the same three BSS patients responded normally, however, to antibodies reactive against the platelet-specific antigen, $\mathrm{PI}^{\mathrm{A} 1}$ (15) (Fig. 2), with two autoantibodies from patients with idiopathic thrombocytopenic purpura, and with a serum containing multiple anti-histocompatibility antigen antibodies obtained from a multitransfused patient (not shown).

Inhibition of ${ }^{51} \mathrm{Cr}$ lysis. We have previously shown that antibody-reactive sites on the platelet surface can be assayed by determining the ability of known numbers of platelets to inhibit the action of a cytolytic antibody on ${ }^{51} \mathrm{Cr}$-labeled target platelets (12). By this means it was found that the BSS platelets contain no detectable sites reactive with quinine- or quinidinedependent antibodies (Fig. 3). The $\mathrm{Pl}^{\mathrm{A} 1}$ antigen was found to be expressed normally on BSS platelets in the same assay (not shown).

Polyacrylamide gel electrophoresis of solubilized platelets with and without pretreatment with enzymes. Platelets from the three BSS patients exhibited a strik-

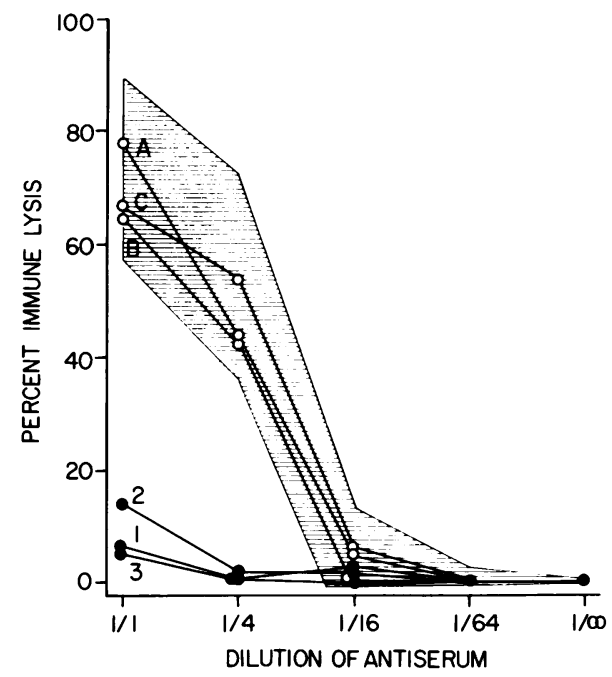

FIGURE 1 Lysis of ${ }^{51} \mathrm{Cr}$-labeled platelets from normal (A, B, C) and BSS $(1,2,3)$ donors by a quinine-dependent, antiplatelet antibody. Ordinate denotes percent release of ${ }^{51} \mathrm{Cr}$ induced by quinine-dependent antiserum in dilutions indicated on the abscissa. Control subjects $A, B$, and $C$ were studied simultaneously with patients 1,2 , and 3 , respectively. The shaded area denotes lysis ( $\pm 2 \mathrm{SD}$ ) observed with platelets from 22 normal individuals. Comparable results were obtained with two quinidine-dependent antibodies.

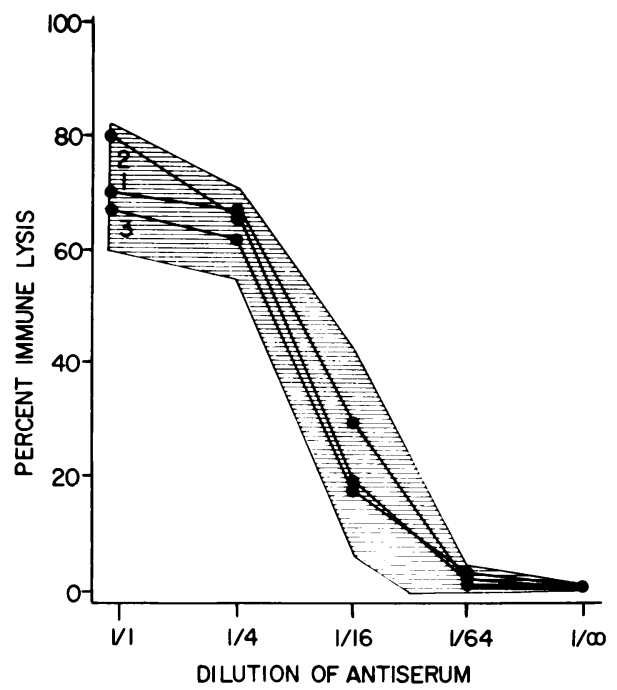

FIGURE 2 Lysis of ${ }^{51} \mathrm{Cr}$-labeled platelets from normal and BSS donors by antibody reactive with the platelet-specific antigen, $\mathrm{Pl}^{\mathrm{A} 1}$ (legend as in Fig. 1). Shaded area denotes lysis $( \pm 2 \mathrm{SD}$ ) observed with platelets from 12 normal individuals including control subjects $\mathrm{A}, \mathrm{B}$, and $\mathrm{C}$. Comparable results were obtained with three different anti-PlA1 antibodies.

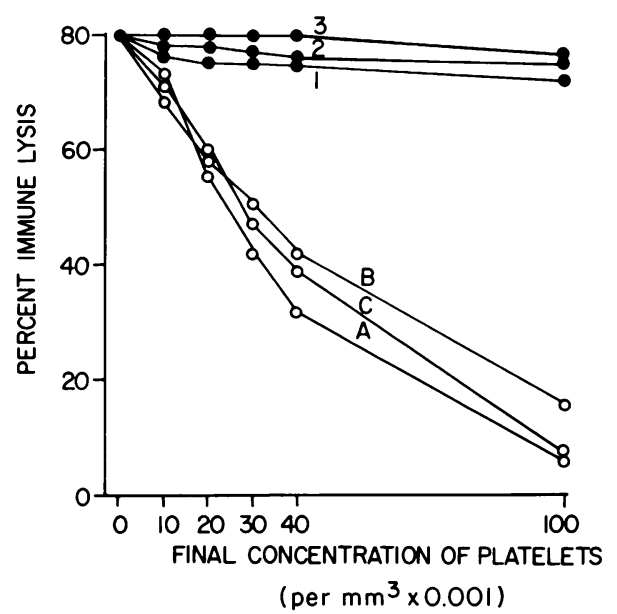

FIGURE 3 Inhibition of the lytic activity of quinidinedependent, antiplatelet antibody by nonlabeled platelets from three BSS patients $(1,2,3)$ and from normal subjects (A, B, C) $20 \mu$ l of nonlabeled platelets in $0.013 \mathrm{M}$ phosphate buffer, $145 \mathrm{mM} \mathrm{NaCl}$, pH 7.4, was incubated with $20 \mu \mathrm{l}$ of quinidine in $0.013 \mathrm{M}$ phosphate buffer, $145 \mathrm{mM} \mathrm{NaCl}, \mathrm{pH}$ 7.4 , and $20 \mu \mathrm{l}$ of quinidine-dependent antibody for $2 \mathrm{~h}$ at $37^{\circ} \mathrm{C}$. The final concentration of quinidine was $10 \mu \mathrm{M}$ and the final concentration of platelets was varied as indicated on the abscissa. Complement and ${ }^{51} \mathrm{Cr}$-labeled platelets were then added and percent immune lysis (ordinate) was determined after an additional $2 \mathrm{~h}$ of incubation. Inhibition curves shown for normal subjects $\mathrm{A}, \mathrm{B}$, and $\mathrm{C}$ are typical of those obtained with 50 normal subjects studied to date. Platelets from the BSS patients failed to inhibit ${ }^{51} \mathrm{Cr}$ release, even at a final platelet concentration of $300 \times 10^{3}$ per $\mathrm{mm}^{3}$ (not shown). BSS platelets inhibited anti-PIA1 antibody to the same extent as platelets from normal subjects (not shown). 
ing reduction of GPI on gels stained with periodic acid Schiff reagent, in confirmation of earlier reports $(8,11)$. Levels of GPIIb and GPIIIa were within normal limits.

GPIb and GPIs of intact normal platelets were hydrolyzed with minimal concentrations of trypsin and chymotrypsin exactly as described by others $(9,10)$. In confirmation of Nurden (10), GPI was completely removed from the membrane by trypsin within $1 \mathrm{~min}$ as judged by visual inspection and scanning of polyacrylamide gel preparations. Chymotrypsin removed GPI more slowly, over a period of $20 \mathrm{~min}$. After $30 \mathrm{~min}$ of treatment with either enzyme, $80 \%$ of the initial quinine-dependent antibody receptor activity remained intact as determined with the inhibition assay.

\section{DISCUSSION}

Our findings indicate that BSS platelets, in contrast to those of all normal subjects tested and those from patients with another inherited disorder of platelet function, Glanzmann's thrombasthenia, are incapable of binding quinidine- and quinine-dependent platelet antibodies in the presence of the appropriate drug. Deletion of the receptor (antigen?) for these antibodies appears to be specific because BSS platelets reacted normally with antibodies having $\mathrm{Pl}^{\mathrm{A} 1}$ and histocompatibility antigen specificities and with autoantibodies from patients with idiopathic thrombocytopenic purpura. The recent finding that BSS platelets are deficient in GPIs and GPIb, the major constituents of platelet membrane GPI $(8,11)$, led us to treat normal platelets with trypsin and chymotrypsin to determine whether reactivity with drug-dependent antibodies would be lost in parallel with GPI. However, antibody receptor activity was preserved almost totally after prolonged treatment of platelets with either enzyme. In normal platelets, the receptors for drug-dependent antibodies are located exclusively on the external surface of the plasma membrane. ${ }^{3}$ Thus, our findings suggest the existence of an abnormality of the BSS platelet membrane in addition to deletion of GPIs and GPIb. Alternatively, the receptor for drug antibodies may lie on a segment of GPIb proximal to the membrane which is not subject to enzymatic degradation.

Acute, severe thrombocytopenia resulting from sensitivity to certain drugs has been recognized as a clinical entity for nearly 100 years. More than $\mathbf{5 0}$ drugs have been implicated as causes of this type of thrombocytopenia but only two, quinidine and quinine, account for at least two-thirds of the observed cases (16). Early workers suggested that thrombocytopenia in this disorder was a consequence of the binding of certain drugs to some constituent of the platelet membrane where they acted as haptenic antigens. Recently ac-

\footnotetext{
${ }^{3}$ Kunicki, T., and R. H. Aster. Unpublished observations.
}

quired evidence, however, suggests a causative role for drug-antibody complexes which have an extremely high affinity for some receptor on the platelet membrane (17). Thus, platelets are destroyed as "innocent bystanders" upon ingestion of the drug. The receptor with which the presumed complexes react has been found on platelets of all normal subjects studied to date, but is not expressed on other blood cells (15).

Our observations appear to provide a new clue to the molecular basis of the functional defect in BSS platelets and suggest that the underlying abnormality in this disorder may be more complex than previously believed. BSS platelets also may provide a new tool for characterization of the membrane receptor with which drug-dependent antibodies react. It seems possible that a more complete understanding of this receptor and of the mechanism of drug-antibody-membrane interaction may be relevant to a spectrum of drug-dependent immunologic phenomena affecting tissues other than platelets.

\section{ACKNOWLEDGMENTS}

We wish to thank Mr. Charles Powell (Milwaukee Blood Center, Inc.) for his capable technical assistance in a segment of this work.

This work was supported by grant HL-13629 from the National Heart, Lung, and Blood Institute and by a research fellowship from Marquette University.

\section{REFERENCES}

1. Caen, J. P., A. T. Nurden, C. Jeanneau, H. Michel, G. Tobelem, S. Levy-Toledano, Y. Sultan, F. Valensi, and J. Bernard. 1976. Bernard-Soulier syndrome: a new platelet glycoprotein abnormality. Its relationship with platelet adhesion to subendothelium and with the Factor VIII von Willebrand protein. J. Lab. Clin. Med. 87: 586-596.

2. Weiss, H. J., T. B. Tschopp, H. R. Baumgartner, I. I. Sussman, M. M. Johnson, and J. J. Egan. 1974. Decreased adhesion of giant (Bernard-Soulier) platelets to subendothelium. Further implications on the role of von Willebrand factor in hemostasis. Am. J. Med. 57: 920-925.

3. Bernard, J., and S. P. Soulier. 1948. Sur une nouvelle variete de dystrophie thrombocytaire hemorragipare congenitale. Sem. Hop. Paris. 24: 217-221.

4. Bithell, T. C., S. J. Parekh, and R. R. Strong. 1972. Platelet function studies in the Bernard-Soulier syndrome. Ann. N. Y. Acad. Sci. 201: 146-160.

5. Caen, J. P., and S. Levy-Toledano. 1973. Interaction between platelets and von Willebrand factor provides a new scheme for primary hemostasis. Nat. New Biol. 244: 159-160.

6. Howard, M. A., R. A. Hutton, and R. M. Hardisty. 1973. Hereditary giant platelet syndrome: a disorder of a new aspect of platelet function. $\mathrm{Br}$. Med. J. 2: 586-588.

7. Phillips, D. R., and P. Poh Agin. 1977. Platelet plasma membrane glycoproteins - evidence for the presence of nonequivalent disulfide bonds using nonreduced-reduced two-dimensional gel electrophoresis. J. Biol. Chem. 252: 2121-2126.

8. Nurden, A. T., and J. P. Caen. 1978. The different glycoprotein abnormalities in thrombasthenic and BernardSoulier platelets. Sem. in Hematol. In press.

9. Okumura, T., C. Lombart, and G. A. Jamieson. 1976. 
Platelet glycocalicin. I. Orientation of glycoproteins of the human platelet surface. J. Biol. Chem. 251: 5944-5949.

10. Nurden, A. T., and J. P. Caen. 1975. Specific roles for platelet surface glycoproteins in platelet function. Nature (Lond.). 255: 720-722.

11. Solum, N. D., I. Hagen, and M. Peterka. 1977. Human platelet glycoproteins. Further evidence that the GPI band from whole platelets contains three different polypeptides one of which may be involved in the interaction between platelets and Factor VIII. Thromb. Res. 10: 71-78.

12. Kunicki, T., and R. H. Aster, 1978. Deletion of the platelet-specific alloantigen $\mathrm{Pl}^{\mathrm{A} 1}$ from platelets in Glanzmann's thrombasthenia. J. Clin. Invest. 61: 1225-1231.

13. Walsh, P. N., D. C. B. Mills, F. I. Pareti, G. J. Stewart, D. E. MacFarlane, M. M. Johnson, and J. J. Egan. 1975. Hereditary giant platelet syndrome-absence of collagen- induced coagulant activity and deficiency of Factor XI binding to platelets. Br. J. Haematol. 29: 639-655.

14. Jamieson, G. A., and T. Okumura. 1978. Reduced thrombin binding and aggregation in Bernard-Soulier platelets. J. Clin. Invest. 61: 861-864.

15. Shulman, N. R., V. J. Marder, M. C. Hiller, and E. M. Collier. 1964. Platelet and leukocyte isoantigens and their antibodies: serologic, physiologic, and clinical studies. Prog. Hematol. 4: 222-304.

16. Aster, R. H. 1977. Thrombocytopenia due to enhanced platelet destruction. In Hematology. W. J. Williams, E. Beutler, A. J. Erslve, and R. W. Rundles, editors. McGraw-Hill Book Co., New York, 2nd edition. 145: 1326-1360.

17. Shulman, N. R. 1964. A mechanism of cell destruction in individuals sensitized to foreign antigens and its implications in autoimmunity. Ann. Intern. Med. 60: 506-521. 